\title{
Adenovirus-mediated delivery of herpes simplex virus thymidine kinase administration improves outcome of recurrent high-grade glioma
}

\author{
Nan Ji1,6,*, Danhui Weng ${ }^{3, *}$, Cang Liu ${ }^{4}$, Zheng Gu${ }^{5}$, Shizhang Chen ${ }^{2}$, Ying Guo ${ }^{2}$, \\ Zhong Fan ${ }^{2}$, Xiao Wang ${ }^{2}$, Jianfei Chen², Yanyan Zhao², Jianfeng Zhou ${ }^{3}$, Jisheng \\ Wang ${ }^{1,6}$, Ding $\mathrm{Ma}^{3}$, Ning $\mathrm{Li}^{2}$ \\ ${ }^{1}$ Department of Neurosurgery, Beijing Tiantan Hospital, Capital Medical University, Beijing, P.R. China \\ ${ }^{2}$ Beijing YouAn Hospital, Capital Medical University, Beijing, P.R. China \\ ${ }^{3}$ Tongji Hospital Affiliated with Tongji Medical College of Huazhong University of Science and Technology, Wuhan, P.R. China \\ ${ }^{4}$ Beijing Friendship Hospital, Capital Medical University, Beijing, P.R. China \\ ${ }^{5}$ Beijing Chao-Yang Hospital, Capital Medical University, Beijing, P.R. China \\ ${ }^{6}$ Beijing Key Laboratory of Brian Tumor, Beijing, P.R. China \\ *These authors have contributed equally to this work \\ Correspondence to: Ding Ma, e-mail: dma@tjh.tjmu.edu.cn \\ Ning Li, e-mail: liningbjyah@vip.sina.com \\ Jisheng Wang, e-mail: neurowang@sina.com \\ Keywords: recurrent high-grade glioma, gene therapy, ADV-TK, glioblastoma \\ Received: September 09,2015 Accepted: November 26, $2015 \quad$ Published: December 23, 2015
}

\section{ABSTRACT}

Background: This randomized, open-label, multicenter, phase II clinical trial was conducted to assess the anti-tumor efficacy and safety of replication-deficient adenovirus mutant thymidine kinase (ADV-TK) in combination with ganciclovir administration in patients with recurrent high-grade glioma (HGG).

Patients and Methods: 53 patients with recurrent HGG were randomly allocated to receive intra-arterial cerebral infusion of ADV-TK or conventional treatments. The primary end point was 6-month progression-free survival (PFS-6). Secondary end points included progression-free survival (PFS), overall survival (OS), safety, and clinical benefit. This trial is registered with Clinicaltrials.gov, NCT00870181.

Results: In ADV-TK group, PFS-6 was 54.5\%, the median PFS was 29.6 weeks, the median OS was 45.4 weeks, and better survivals were achieved when compared with control group. The one-year PFS and OS were $22.7 \%$ and $44.6 \%$ in ADV-TK group respectively, and clinical benefit was $68.2 \%$. There are 2 patients alive for more than 4 years without progression in ADV-TK group. In the subgroup of glioblastoma received ADV-TK, PFS-6 was 71.4\%, median PFS was 34.9 weeks, median OS was 45.7 weeks respectively, much better than those in control group. The one-year PFS and OS were $\mathbf{3 5 . 7 \%}$ and $\mathbf{5 0 . 0 \%}$ in ADV-TK group respectively. ADV-TK/ganciclovir gene therapy was well tolerated, and no treatment-related severe adverse events were noted.

Conclusion: Our study demonstrated a notable improvement of PFS-6, PFS and OS in ADV-TK treated group, and the efficacy and safety appear to be comparable to other reported treatments used for recurrent HGG. ADV-TK gene therapy is therefore a valuable therapeutic option for recurrent HGG.

\section{INTRODUCTION}

Treatment options for patients with recurrent GBMs and AAs remain limited. The treatments include resection with or without carmustine (bis-chloroethylnitrosourea, BCNU) wafer placement in selected patients with local recurrence, radiotherapy, chemotherapy, the antiangiogenic agent bevacizumab alone or in combination 
with chemotherapy, or alternating electric field therapy [1]. Surgery prolongs survival only to a limited degree, and the benefits of repeated radiotherapy are unclear. The repeated administration of TMZ with the same schedule of the initial treatment has not generally been recommended in recurrent patients due to the risk of cumulative toxicity and to the possibility of chemotherapy resistance. Development of alternative treatment modalities, preferably with mechanisms of action dissimilar to those of standard therapies, is therefore urgently needed.

Most brain tumors are localized lesions of rapidly dividing cells in a background of non-dividing neurons. They rarely metastasize outside of the central nervous system, and recurrence occurs usually at the site of original lesion, making them highly amenable to gene therapy. Thus, several gene-therapy approaches have been studied in glioma. The first clinical gene therapy trials against brain cancer were registered in 1992, using the ex-vivo modification of autologous tumor cells with a retrovirus to express the gene encodinginterleukin-2 in relapsed/ refractory neuroblastoma [2]. Later, herpes simplex virus (HSV) thymidine kinase (TK) suicide gene therapy using retrovirus-producing packaging cells, followed by intravenous ganciclovir therapy was reported to be used in primary [3] and recurrent $[4,5]$ rain-cancer patients. Two phase I studies demonstrated the safety and efficacy of replication-deficient adenovirus HSV-TK/ganciclovir gene therapy by comparing with replication-deficient retrovirus therapy or retrovirus-producing packaging cells therapy [6, 7]. In 2004, Immonen et al. reported the first randomized, controlled clinical trial with non-replicable adenovirus HSV-TK/ganciclovir (AdHSV-TK/ganciclovir) gene therapy. AdHSV-TK/ganciclovir gene therapy increased the median survival time and was well tolerated without significant safety issues [8].

Building on these promising results, an international, open-label, randomized, parallel group multicenter phase III clinical trial using the first-generation replicationdeficient adenovirus containing the cDNA for HSV-TK (sitimagenecer adenovec; Cerepro ${ }^{\circledR}$, Ark Therapeutics Ltd., London, UK) for newly diagnosed operable HGG patients was reported recently [9]. Their results showed that additional Cerepro ${ }^{\circledR}$ therapy prolonged median time to death or re-intervention of the patients, there was no difference between groups in terms of overall survival (OS), and patients received Cerepro ${ }^{\circledR}$ suffered more treatment-related adverse events, such as hemiparesis and aphasia. Although this study made a step forward from the earlier retrovirus-based phase III study, the limitation of the efficacy of Cerepro ${ }^{\circledR}$ may due to the transduction efficiency.

In 2007, our research group reported the encouraging clinical results of ADV-TK/ganciclovir therapy in advanced hepatocellular carcinoma (HCC). This phase II clinical trial revealed increased survival and safety in the non-vascular invasion HCC patients who received liver transplantation and $\mathrm{ADV}-\mathrm{TK} /$ ganciclovir adjuvant gene therapy; the 3-year overall survival (OS) rate was $100 \%$ and the recurrence-free survival (RFS) rate was $83.3 \%$ [10]. In 2009, we reported a phase I clinical trial with ADV-TK/GCV therapy in 18 patients with head and neck cancer and nasopharyngeal carcinoma (NPC), with the aim to determine the safety profile, humoral immune response and biologic activity of a single intratumor injection of ADV-TK followed by GCV therapeutic approach [11]. Our findings suggested that ADV-TK gene therapy can be administered safely to cancer patients, and achieved a local response with few environmental effects.

Intra-arterial chemotherapy is a strategy of dose intensification that results in more concentrated and localized delivery of chemotherapy to brain tumors. Since ADV-TK showed good tolerance and safety, we designed a randomized, open-label, multicenter, phase II clinical trial to assess the anti-tumor efficacy and safety of intraarterial cerebral infusion of ADV-TK in combination with systemic intravenous ganciclovir in patients with recurrent malignant glioma.

\section{RESULTS}

\section{Patient characteristics and treatment}

A total of 53 patients were enrolled from three centers in randomization, 27 patients allocated in ADV-TK group and 26 patients allocated in the control group. There were 7 patients, 3 in ADV-TK group and 4 in control group, withdrew after randomization for refusing to continue the trial. In ADV-TK group, one patient was lost to follow-up after two cycles of gene therapy, and one patient refused to continue medical treatment after completing three cycles of treatment. Finally, 44 patients were therefore included in the PFS, OS, and safety analyses, 22 patients in ADV-TK group and 22 patients in control group (CONSORT diagram, Figure 1). Demographic data are listed in Table 1. Baseline characteristics were similar between the two groups.

At the time of analysis, the median duration of follow-up was 31.2 weeks (range 1.1-238.4 weeks) for 44 patients. Main outcomes are listed in Table 2.

\section{PFS-6, PFS and OS in ADV-TK treated group and control group}

In ADV-TK treated group, the PFS-6 rate and median PFS were 54.5\% and 29.6 weeks (range 7.9-238.4 weeks) respectively, much better than those in control group (PFS-6 = 13.6\%; median PFS = 8.4 weeks, ranging 1.139.1 weeks). The actuarial probability of PFS rates was significantly different between two groups (HR: 0.315; 95\% CI: 0.161 to $0.615 ; P=0.001$ ) (Figure $2 \mathrm{~A}$ ). At the end of the investigation, the median OS was 45.4 weeks 
(range 7.9-238.4 weeks) in ADV-TK treated group, more longer than that in control group (14.3 weeks, ranging 1.1-45.6 weeks). The difference in the OS rates between these two groups was significant (HR: $0.207 ; 95 \% \mathrm{CI}$ : 0.096 to $0.444 ; P<0.001$ ) (Figure $2 \mathrm{~B}$ ). The one-year PFS rate and $O S$ rate were $22.7 \%$ and $44.6 \%$ respectively in ADV-TK group. Among the 22 patients who received ADV-TK treatment, two patients remained alive until Oct 2014. In the control group, all patients died within one year. Adjustment by the Cox regression model did not substantially alter the results (Table 2).

\section{Objective response and overall clinical benefit in the ADV-TK group}

All 22 patients in the ADV-TK group received objective-response evaluation at the end of the second treatment cycle. No complete response was observed in any patient. One patient was partial response (4.5\%), 14 patients achieved stable disease $(63.6 \%)$, and disease progression was observed in seven patients during treatment $(31.8 \%)$. The clinical benefit (complete response, plus partial response, plus stable disease) of ADV-TK therapy was $68.2 \%$ at the end of the second cycle.

\section{PFS-6, PFS and OS for glioblastoma patients}

There were 32 patients with recurrent glioblastoma, 14 patients in the ADV-TK group and 18 patients in the control group. The PFS-6 rate was $71.4 \%$ in the ADVTK group and $5.6 \%$ in the control group. Median PFS was 34.9 weeks (range 9.0-238.4 weeks) in the ADV-TK group and 7.4 weeks (range 1.1-35.3 weeks) in the control group respectively, showing the significant difference between these two groups (HR: $0.157 ; 95 \% \mathrm{CI}: 0.062$ to $0.398 ; P<0.001$ ) (Figure 3A). The median OS was 45.7 weeks (range 9.0-238.4 weeks) in the ADV-TK group and illustrated significant improvement when compared with control group (8.6 weeks, ranging 1.1-45.0 weeks) (HR: $0.125 ; 95 \%$ CI: 0.044 to $0.356 ; P<0.001$ ) (Figure 3B). The one-year PFS and OS rates in ADV-TK group were $35.7 \%$ and $50.0 \%$ respectively, with only one patient living till Oct 2014 (Table 2). All patients alive less than one year in the control group.

\section{Safety}

ADV-TK treatment was well tolerated, and no treatment-related severe adverse events were observed. Mild catarrhal symptoms were reported in $5 / 22$ patients

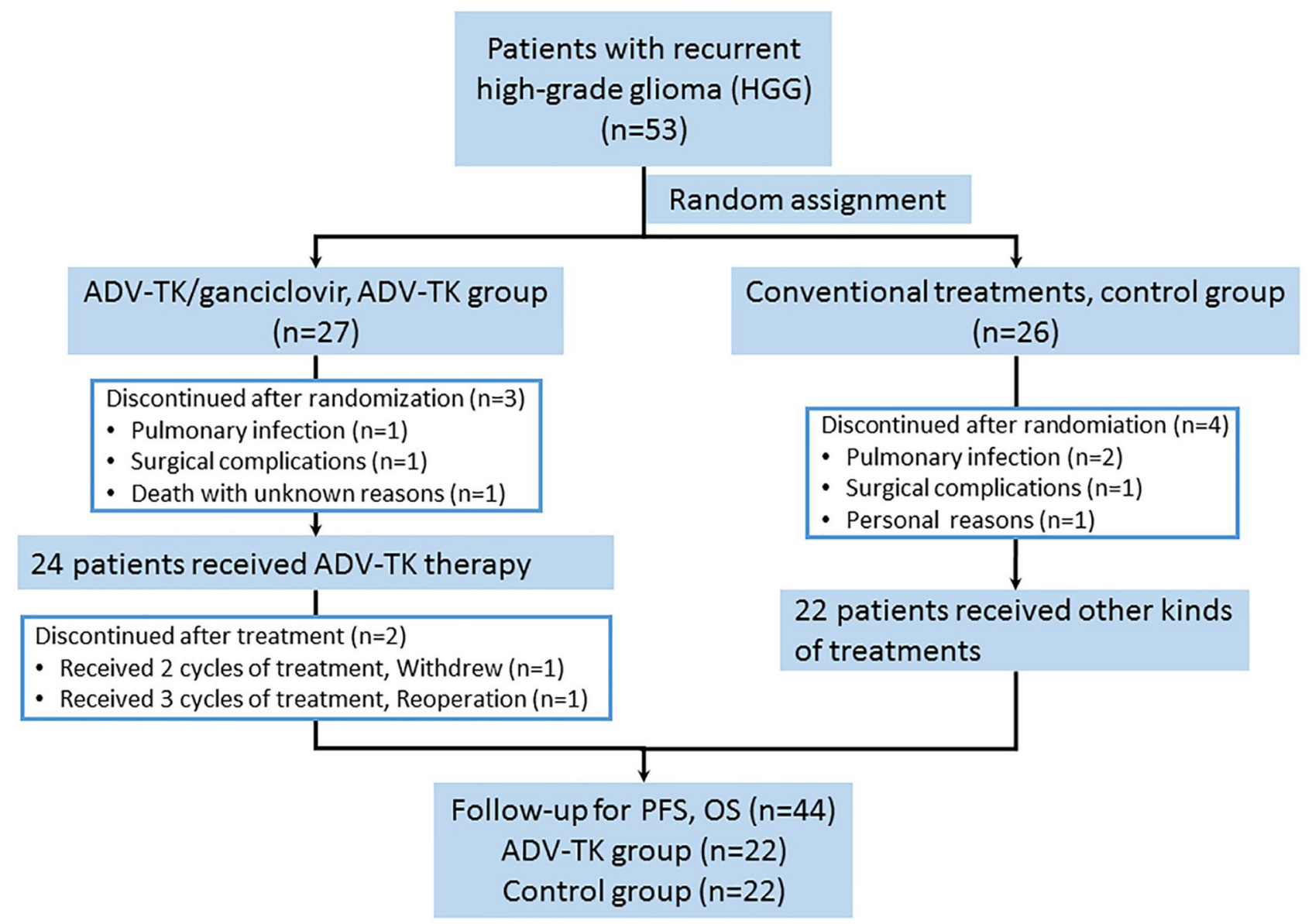

Figure 1: CONSORT diagram. 
Table 1: Patient demographic and clinical characteristics

\begin{tabular}{|c|c|c|c|}
\hline Characteristic & ADV-TK group $(n=22)$ & Control group $(n=22)$ & $\boldsymbol{P}$ \\
\hline Sex & & & 0.314 \\
\hline Male & 18 & 15 & \\
\hline Female & 4 & 7 & \\
\hline Age (yr) & & & 0.86 \\
\hline Median & 49 & 54 & \\
\hline Range & $28-71$ & $20-69$ & \\
\hline WHO tumor grade & & & 0.314 \\
\hline Grade 3 & 8 & 4 & \\
\hline Grade 4 & 14 & 18 & \\
\hline \multicolumn{4}{|l|}{ Histology } \\
\hline AA/AO/AG/OTHERS & 8 & 4 & 0.108 \\
\hline Glioblastoma & 14 & 18 & \\
\hline $\begin{array}{l}\text { Time interval before } \\
\text { randomization (Week) }\end{array}$ & & & 0.387 \\
\hline Median/Mean & $2.7 / 6.3$ & $3.4 / 7.6$ & \\
\hline Range & $0-55.6$ & $0-32.7$ & \\
\hline History of initial treatment & & & 0.135 \\
\hline Surgery only & 1 & 3 & \\
\hline $\begin{array}{l}\text { Surgery }+ \\
\text { radiochemotherapy }\end{array}$ & 18 & 11 & \\
\hline Surgery + chemotherapy & 1 & 5 & \\
\hline Surgery + radiotherapy & 2 & 3 & \\
\hline
\end{tabular}

Table 2: Progression-free and overall survival

\begin{tabular}{|c|c|c|c|c|c|c|}
\hline Comparison & $\begin{array}{l}\text { Median } \\
\text { Survival } \\
\text { (weeks) }\end{array}$ & $\begin{array}{c}\text { Minimum } \\
\text { Survival } \\
\text { (weeks) }\end{array}$ & $\begin{array}{c}\text { Maximum } \\
\text { Survival } \\
\text { (weeks) }\end{array}$ & HR & $95 \% \mathrm{CI}$ & $\boldsymbol{P}$ \\
\hline \multicolumn{7}{|l|}{ Progression-free Survival } \\
\hline \multicolumn{7}{|l|}{ Overall } \\
\hline ADV-TK v Control & $29.6 v 8.4$ & $7.9 v 1.1$ & $238.4 v 39.1$ & 0.315 & 0.161 to 0.615 & 0.001 \\
\hline \multicolumn{7}{|l|}{ GBM Subgroup } \\
\hline ADV-TK $v$ Control & $34.9 \vee 7.4$ & $9.0 v 1.1$ & $238.4 v 35.3$ & 0.157 & 0.062 to 0.398 & $<0.001$ \\
\hline \multicolumn{7}{|l|}{ Overall Survival } \\
\hline \multicolumn{7}{|l|}{ Overall } \\
\hline ADV-TK $v$ Control & $45.4 v 14.3$ & $7.9 v 1.1$ & $238.4 v 45.6$ & 0.207 & 0.096 to 0.444 & $<0.001$ \\
\hline \multicolumn{7}{|l|}{ GBM Subgroup } \\
\hline ADV-TK $v$ Control & $45.4 v 8.6$ & $9.0 v 1.1$ & $238.4 v 45.0$ & 0.125 & 0.044 to 0.356 & $<0.001$ \\
\hline
\end{tabular}

Abbreviation: HR, hazard ratio; CI, confidence interval. $\mathrm{HRs}_{1}<1$ indicate benefit with ADV-TK. 
who received ADV-TK therapy. Slight fever with no chills was also observed after injection of ADV-TK during the first three days in the same five patients (temperature range $37.3-38.3^{\circ} \mathrm{C}$ ). Three of these five patients also suffered from light headache. All of these symptoms subsided within six days. One patient in the ADV-TK group experienced cerebral vasospasm 10 days after ADV-TK treatment. Hematological toxicity mainly consisted of grade 1 to 2 neutropenia, with only one patient in each group developing grade 3 neutropenia. There was no evidence of liver or kidney dysfunction caused by ADV-TK in our study with no significant difference between two groups. Toxicity experienced only during the first eight weeks of treatment was compared (Table 3).

\section{DISCUSSION}

Tumor-treatment strategies for recurrent HGGs remain imprecise. The lack of randomized studies comparing use of these agents with best supportive care may be an important limitation to determining the most effective tumor-treatment strategy. Recently, clinical trials demonstrating improved PFS-6 rates of up to $50 \%$ and response rates of up to $57 \%$ have resulted in accelerated United States Food and Drug Administration (FDA) approval of bevacizumab in patients with recurrent glioblastoma [1], but its use is associated with toxicities, eventual treatment resistance, and the potential for progression to a more invasive tumor phenol type. The unique combination of the

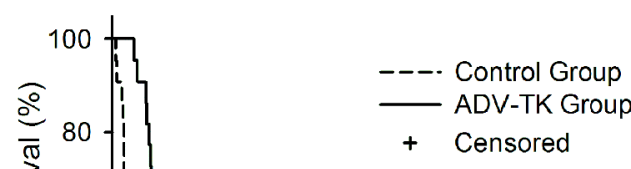

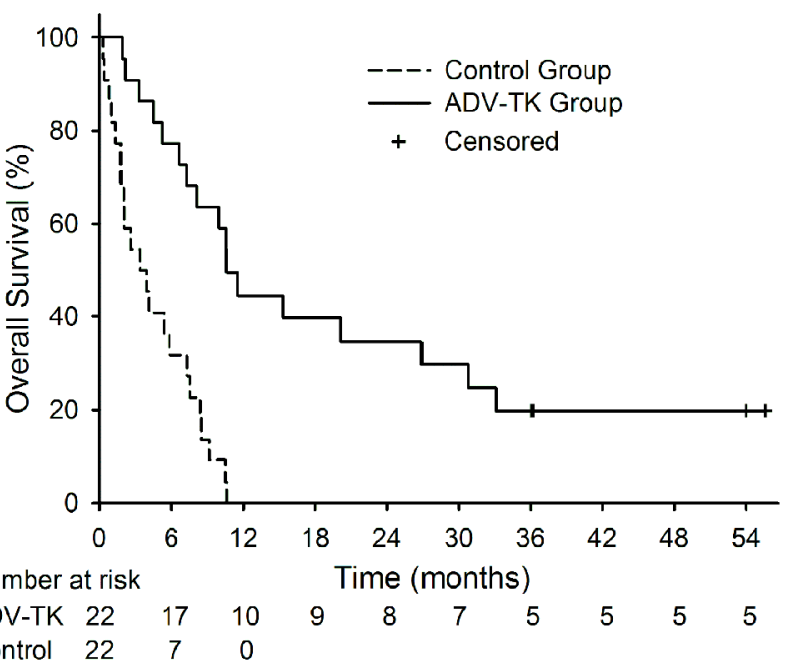

Figure 2: Kaplan-Meier plots for Progression-free Survival (PFS) and Overall Survival (OS). A. PFS for ADV-TK group versus Control group. B. OS for ADV-TK group versus Control group.

A

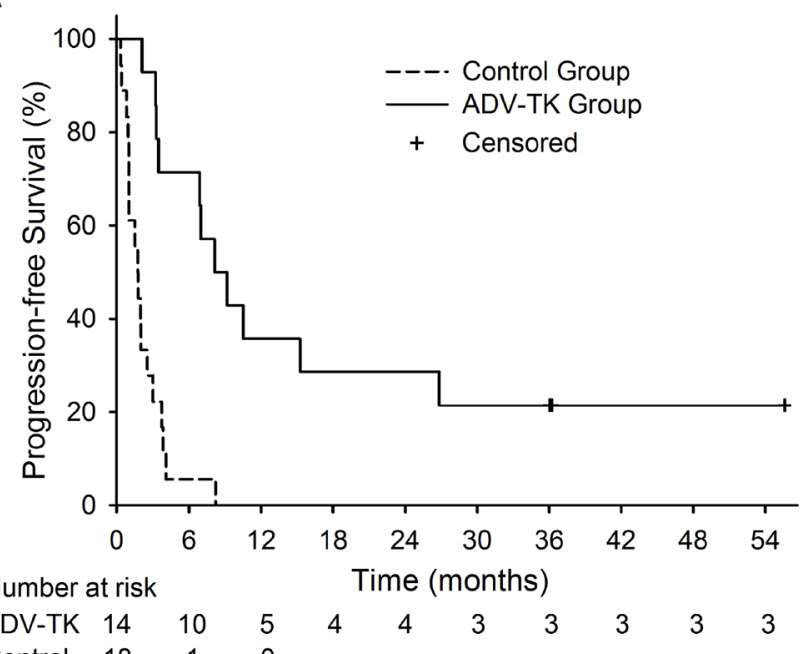

B

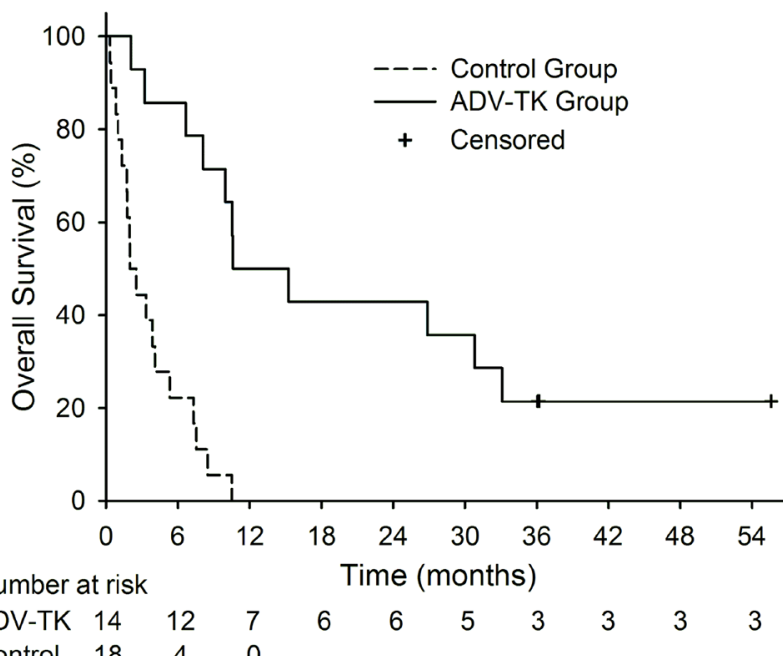

Figure 3: Kaplan-Meier plots for Progression-free Survival (PFS) and Overall Survival (OS) in GBM subgroup. A. PFS for ADV-TK group versus Control group. B. OS for ADV-TK group versus Control group. 
Table 3: Toxicity of adv-tk in patients with malignant recurrent glioma

\begin{tabular}{|c|c|c|c|c|}
\hline Toxicity & $\begin{array}{c}\text { Grade } \\
\text { (NCI-CTC) }\end{array}$ & $\begin{array}{c}\text { ADV-TK group }(n=22) \\
\text { No. of Patients }(\%)\end{array}$ & $\begin{array}{l}\text { Control group }(n=22) \\
\text { No. of Patients }(\%)\end{array}$ & $P$ \\
\hline Catarrhal symptoms & & $5(22.7 \%)$ & - & - \\
\hline \multirow[t]{4}{*}{ Anemia } & & $4(18.2 \%)$ & $6(27.3 \%)$ & 0.910 \\
\hline & I & $2(9.1 \%)$ & $2(9.1 \%)$ & \\
\hline & II & $1(4.5 \%)$ & $2(9.1 \%)$ & \\
\hline & III & $1(4.5 \%)$ & $2(9.1 \%)$ & \\
\hline \multirow[t]{4}{*}{ Neutropenia } & & $6(36.4 \%)$ & $7(31.8 \%)$ & 0.878 \\
\hline & I & $2(9.1 \%)$ & $3(13.6 \%)$ & \\
\hline & II & $3(13.7 \%)$ & $3(13.6 \%)$ & \\
\hline & III & $1(4.5 \%)$ & $1(4.5 \%)$ & \\
\hline \multirow[t]{3}{*}{ Thrombocytopenia } & & $4(18.2 \%)$ & $3(13.6 \%)$ & 0.915 \\
\hline & I & $3(13.2 \%)$ & $2(9.1 \%)$ & \\
\hline & II & $1(4.5 \%)$ & $1(4.5 \%)$ & \\
\hline Nausea/vomiting & I & $7(31.8 \%)$ & $6(27.3 \%)$ & 0.815 \\
\hline Cerebral vasospasm & I & $1(4.5 \%)$ & 0 & - \\
\hline \multirow[t]{3}{*}{ ALT } & & $3(13.2 \%)$ & $6(27.3 \%)$ & 0.396 \\
\hline & I & $1(4.5 \%)$ & $5(22.7 \%)$ & \\
\hline & II & $2(9.1 \%)$ & $1(4.5 \%)$ & \\
\hline AST & I & $3(13.2 \%)$ & $5(22.7 \%)$ & 0.722 \\
\hline
\end{tabular}

Abbreviation: NCI-CTC, National Cancer Institute Common Terminology Criteria for Adverse Events; ALT, alanine aminotransferase; AST, aspartate aminotransferase.

high mitotic activity of tumor cells and the mostly post-mitotic environment of the adult brain, as well as aggression within the local environment within the closed compartment of the central nervous system [12], have been the subjects of many gene-therapy studies. Table 4 contains the most recent and clinically relevant approaches to virus-mediated gene therapy of recurrent HGGs. Although all of these clinical trials were phase I to II and included limited numbers of patients, their encouraging results highlight the general safety of the approach and their potential role in the treatment of recurrent HGGs.

Our phase II, randomized clinical trial demonstrated clear progression-free survival and overall survival benefit associated with ADV-TK gene therapy, which was also shown to be safe. Even though our trial includes a small number of patients, to our knowledge this patient group is the largest of those included in adenovirus gene-therapy clinical trials with recurrent HGGs.

The results of our current investigation present an advantage in the strategy of administration of ADV-TK gene reagent. In order to disrupt the blood-brain barrier, mannitol was administrated just before every ADV$\mathrm{TK} /$ ganciclovir intra-arterial infusion. Mannitol has been used as regular clinical treatment for intracranial hypertension for many years [24, 25]. As early as 1972, Raport et al proposed the theory of application of hypertonic solution to open the blood-brain barrier [26]. Later, Neuwelt et al applied the theory in the intraarterial chemotherapy in brain tumor [27]. In our study, ADV-TK/ganciclovir intra-arterial infusion brought it's superiority into full efficiency by assist of mannitol administration. The values of PFS-6 rate, median PFS and median OS in our study were significantly higher than those among the relevant virus-mediated gene therapy clinical trials (Table 4), and also better than those of the clinical trials with chemotherapy and NovoTTF100A (Supplementary Table).

We previously reported two clinical trials supporting the efficacy and safety of ADV-TK gene therapy [10, 11]. The adverse effects in present investigation were consistent with our previous studies. Fever was one of the most common treatment-related adverse events and may be due to a physical immune response to the vector. 
Table 4: Clinical trials with gene therapy for recurrent HGG patients

\begin{tabular}{|c|c|c|c|c|c|c|c|}
\hline $\begin{array}{l}\text { Gene } \\
\text { Therapy }\end{array}$ & Author (year) & $\begin{array}{l}\text { Tumor } \\
\text { Type }\end{array}$ & Phase & $\begin{array}{l}\text { No. of } \\
\text { Patients }\end{array}$ & $\begin{array}{l}\text { PFS-6 } \\
(\%)\end{array}$ & $\begin{array}{c}\text { Median } \\
\text { PFS } \\
\text { (months) }\end{array}$ & Median OS (months) \\
\hline \multirow[t]{5}{*}{$\begin{array}{l}\text { AdHSV- } \\
\text { TK/GCV }\end{array}$} & Trask et al. $(2000)^{13}$ & $\begin{array}{l}\text { Recurrent } \\
\text { GBM }\end{array}$ & I & 13 & $\mathrm{~N} / \mathrm{A}$ & N/A & $\begin{array}{c}4.0(\text { post-GT) } \\
20.9(\text { post-DX) }\end{array}$ \\
\hline & Judy and Eck (2002) ${ }^{14}$ & $\begin{array}{l}\text { Primary } \\
\text { and } \\
\text { recurrent } \\
\text { GBM }\end{array}$ & I & 13 & $\mathrm{~N} / \mathrm{A}$ & 3 & 10.0 \\
\hline & $\begin{array}{l}\text { Germano et al. } \\
\qquad(2003)^{15}\end{array}$ & $\begin{array}{l}\text { Recurrent } \\
\text { GBM }\end{array}$ & I & 11 & N/A & N/A & $\begin{array}{l}12.0 \text { (post-GT) } \\
22.0 \text { (post-DX) }\end{array}$ \\
\hline & Smitt et al. $(2003)^{16}$ & $\begin{array}{l}\text { Recurrent } \\
\text { GBM }\end{array}$ & I & 14 & $\mathrm{~N} / \mathrm{A}$ & 2.3 & 4.0 \\
\hline & Immonen et al. $(2004)^{8}$ & $\begin{array}{l}\text { Primary } \\
\text { and } \\
\text { recurrent } \\
\text { GBM }\end{array}$ & $\begin{array}{c}\text { II } \\
\text { Randomized }\end{array}$ & $\begin{array}{c}36 \text { (all) } \\
17(\mathrm{GT}) \\
19 \\
\text { (Control) }\end{array}$ & $\mathrm{N} / \mathrm{A}$ & $\mathrm{N} / \mathrm{A}$ & $\begin{array}{c}62.4 \text { weeks }(\mathrm{GT}) \\
55.3 \text { weeks }(\mathrm{GBM})\end{array}$ \\
\hline Ad-p53 & Lang et al. $(2003)^{17}$ & $\begin{array}{l}\text { Recurrent } \\
\text { GBM }\end{array}$ & I & 15 & $\begin{array}{l}33.3 \% \\
(5 / 15)\end{array}$ & 13 weeks & 43 weeks \\
\hline $\begin{array}{l}\text { ONYX- } \\
015\end{array}$ & Chiocca et al. (2004) & $\begin{array}{c}\text { Recurrent } \\
\text { HGG }\end{array}$ & I & 24 & $\mathrm{~N} / \mathrm{A}$ & 46 days & $\begin{array}{c}6.2(\text { all }) \\
4.9(\mathrm{GBM})\end{array}$ \\
\hline \multirow[t]{2}{*}{ G207 } & Markert et al. $(2000)^{19}$ & $\begin{array}{l}\text { Recurrent } \\
\text { GBM }\end{array}$ & I & 21 & $\mathrm{~N} / \mathrm{A}$ & $\begin{array}{c}3.5 \text { (all, } \\
\text { mean) }\end{array}$ & $\begin{array}{c}12.8 \text { (alive, mean) } \\
6.2 \text { (dead, mean) } \\
15.9 \text { (GBM, post-DX, } \\
\text { mean })\end{array}$ \\
\hline & Market et al. $(2009)^{20}$ & $\begin{array}{l}\text { Recurrent } \\
\text { GBM }\end{array}$ & $\mathrm{Ib}$ & 6 & N/A & 3.0 & $\begin{array}{c}6.6 \text { (post-GT) } \\
23.0(\text { post-DX) }\end{array}$ \\
\hline \multirow[t]{3}{*}{ HSV1716 } & $\begin{array}{l}\text { Rampling et al. } \\
\qquad(2000)^{21}\end{array}$ & $\begin{array}{l}\text { Recurrent } \\
\text { MG }\end{array}$ & I & 9 & $\mathrm{~N} / \mathrm{A}$ & $\begin{array}{c}\text { N/A } \\
\text { Range: } 2.0 \\
\sim 24.0\end{array}$ & $\begin{array}{c}\mathrm{N} / \mathrm{A} \\
\text { Range: } 8 \text { weeks } \sim 24 \\
\text { months }\end{array}$ \\
\hline & $\begin{array}{l}\text { Papanastassiou et al. } \\
\qquad(2002)^{22}\end{array}$ & $\begin{array}{l}\text { Primary } \\
\text { and } \\
\text { recurrent } \\
\text { GBM }\end{array}$ & I & 12 & N/A & N/A & $\begin{array}{l}\text { greater than } 7.0 \\
\text { Range: } 1.0 \sim 13.0\end{array}$ \\
\hline & Harrow et al. $(2004)^{23}$ & $\begin{array}{l}\text { Primary } \\
\text { and } \\
\text { recurrent } \\
\text { GBM }\end{array}$ & $\mathrm{N} / \mathrm{A}$ & 12 & $\begin{array}{c}50 \% \\
(6 / 12)\end{array}$ & N/A & $\begin{array}{c}\mathrm{N} / \mathrm{A} \\
\text { Range: } 3.0-22.0\end{array}$ \\
\hline
\end{tabular}

Abbreviation: PFS, progression-free survival; PFS-6, 6-month progression-free survival; OS, overall survival; MG, malignant gliomas; GBM, glioblastoma; HGG, high grade glioma; DX, diagnosis; GT, gene therapy; N/A, data not available.

Another adverse effect was hematological toxicity which mainly consisted of grade 1 to 2 neutropenia. There were three patients had light headache after treatment which was supposed to the physiological reaction of mannitol administration. Fortunately, all of these responses were transient and easy to tolerate.
The number of patients enrolled in the current clinical trials is the largest patient population among the virus-mediated gene therapy trials in Table 4, but is still small size of clinical trials. The next we need to do is to increase the number of patients and compare with a single agent or a combination regimen containing 
TMZ, bevacizumab, or irinotecan. Concerning local gene therapy, the greatest shortcoming of non-replicating adenovirus gene therapy appears to be the low transduction efficiency of the vector and its limited distribution. Recently, our research group developed a series of conditionally replicating virus vectors [28-30], by which therapeutic gene should express more effectively in target tumor cells. It will be a good choice for further studies of ADV-TK gene therapy in the treatment of malignant tumors.

\section{MATERIALS AND METHODS}

This study was conducted in accordance with the Declaration of Helsinki. All participating institutions obtained local ethics approval and written informed consent from all patients. This trial is registered with ClinicalTrials.gov. NCT00870181.

\section{Patients}

From November 2009 to December 2012, patients were enrolled at Beijing Tiantan Hospital, Beijing ChaoYang Hospital, and Beijing Friendship Hospital. Eligible patients were adults of either sex with histologically confirmed WHO grades 3 to 4 malignant glioma (glioblastoma multiforme, anaplastic astrocytoma, or anaplastic oligodendroglioma) who had just received diagnoses of recurrence or progression based on clinical or radiological evidence upon presentation to the centers. Patients were fit for intra-arterial infusion and intravenous chemotherapy, with adequate hepatic, renal, and hematologic function. Evidence of recurrence or progression was confirmed by evaluable enhancing recurrent tumor on contrast-enhanced magnetic resonance imaging before and after the treatment. Patients with primary WHO grade 1 to 2 glioma were pathologically verified with disease recurrence or progression to WHO grade 3 to 4 . Additional eligibility criteria included legal age $\geq 18$ years, an Eastern Cooperative Oncology Group performance $\geq 2$, chemotherapy completion $\geq 4$ weeks prior, and recovery from drug-induced toxicities. The exclusion criteria were active pregnancy, prior gene therapy, second primary tumor, gravidity, lactation, hypersensitivity to antiviral drugs, immunological deficit, active uncontrolled infections, or requiring treatment with warfarin or any other anticoagulants.

\section{Treatment}

Patients were randomly allocated to either the ADV-TK group or to the control group according to the random table kept in Tiantan Hospital affiliated with Capital Medical University (Beijing, P.R. China). ADV$\mathrm{TK}$ is a chimeric human group $\mathrm{C}$ adenovirus (ADV5) that expresses the gene encoding HSV-TK under the control of a Rous sarcoma virus long terminal repeat promoter, which is inserted in the region of the excised E1 adenoviral genes. In the ADV-TK group, ADV-TK (Tian Dakang Co.) was administered via intra-arterial cerebral infusion. Based on the toxicity results from our previous study, a total of $1 \times 10^{12}$ viral particles of ADV-TK was administered in the current clinical trial [10].

Systemic ganciclovir therapy was delivered at a dose of $5 \mathrm{mg} / \mathrm{kg}$ intravenous, every $12 \mathrm{~h}$ at $36 \mathrm{~h}$ after ADV-TK therapy for 14 days. Mannitol (25\% 1.4 M mannitol, 250 $\mathrm{ml} / 15$ minutes) was given just before every ADV-TK / ganciclovir infusion to disrupt the blood-brain barrier. The ADV-TK/ganciclovir treatment was repeated every 21 days for at least two cycles. Patients in the control treatment group received surgery or systemic chemotherapy or palliative care. Imaging (using the same contrast-enhanced imaging method as the baseline scan) was repeated on clinical progression wherever possible; scans were also performed at baseline and at the end the second and fourth cycles for the ADV-TK group, with progressive disease defined as a $\geq 25 \%$ increase in two-dimensional tumor size. Safety was assessed according to National Cancer Institute Common Terminology Criteria for Adverse Events (Version 3.0).

\section{Study measures and statistical analysis}

The primary end point was PFS-6. Secondary end points included PFS, OS, safety, objective response rate (complete response, partial response, stable disease, and progressive disease), and clinical benefit (complete response, plus partial response, plus stable disease). PFS and OS were calculated from the day of randomization until the event (progression confirmed either radiologically or clinically if scan not performed or death) happened or until the patient was censored. Event-free patients were censored on the date of last follow-up.

Kaplan-Meier curves were compared using the log-rank test. Treatment hazard ratios (HRs) with a 95\% confidence interval (CI) were calculated using the Cox regression model. For comparisons against the control group, $\mathrm{HR}<1$ indicate benefit with ADV-TK. Hypothesis testing was two-sided. $P$ values $<0.05$ were considered to indicate statistical significance. Data were analyzed with SPSS statistical software (version $18 \cdot 0$ for Windows, SPSS).

\section{ROLE OF THE FUNDING SOURCE}

Foundation for the Excellent Medical Staff of Beijing (2011-3-034); National Major Scientific and Technological Special Project for "Significant New Drugs Development" during the Twelfth Five-year Plan Period (2011ZX09101-001-10, 2012ZX100002017009); Beijing Municipal Administration of Hospitals Clinical Medicine Development of Special Funding Support (ZY201311); National Key Technology Research and Development Program of the Ministry of Science 
and Technology of China (2014BAI04B02); National Science Foundation of China (No. 81230038, 81472783, 81090414 and 81025011) and the "973" Program of China (No. 2015CB553903).

\section{CONFLICTS OF INTEREST}

The authors declare no conflicts of interest.

\section{REFERENCES}

1. National Comprehensive Cancer Network. NCCN Guidelines Version 2.2011: Central Nervous System Cancers. Available at: www.nccn.org. Accessed August 16, 2011.

2. Phase I study of cytokine-gene modified autologous neuroblastoma cells for treatment of relapsed/refractory neuroblastoma. Human Gene Therapy. 1992;3:665-76. doi:10.1089/hum.1992.3.6-665

3. Oldfield EH, Ram Z, Culver KW, Blaese RM, DeVroom HL, Anderson WF. Gene therapy for the treatment of brain tumors using intra-tumoral transduction with the thymidine kinase gene and intravenous ganciclovir. Hum Gene Ther. 1993;4:39-69. doi:10.1089/hum.1993.4.1-39

4. Ram Z, Culver KW, Oshiro EM, Viola JJ, DeVroom HL, Otto E, Long Z, Chiang Y, McGarrity GJ, Muul LM, Katz D, Blaese RM, Oldfield EH. Therapy of malignant brain tumors by intratumoral implantation of retroviral vectorproducing cells. Nat Med. 1997;3:1354-61.

5. Klatzmann D, Valéry CA, Bensimon G, Marro B, Boyer O, Mokhtari K, Diquet B, Salzmann JL, Philippon J. A phase I/II study of herpes simplex virus type 1 thymidine kinase "suicide" gene therapy for recurrent glioblastoma. Study Group on Gene Therapy for Glioblastoma. Hum Gene Ther. 1998;9:2595-604. doi:10.1089/hum.1998.9.17-2595

6. Puumalainen AM, Vapalahti M, Agrawal RS, Kossila M, Laukkanen J, Lehtolainen P, Viita H, Paljärvi L, Vanninen R, Ylä-Herttuala S. Beta-galactosidase gene transfer to human malignant glioma in vivo using replication-deficient retroviruses and adenoviruses. Hum Gene Ther. 1998; 9:1769-74. doi:10.1089/hum.1998.9.12-1769

7. Sandmair AM, Loimas S, Puranen P, Immonen A, Kossila M, Puranen M, Hurskainen H, Tyynelä K, Turunen M, Vanninen R, Lehtolainen P, Paljärvi L, Johansson R, et al. Thymidine kinase gene therapy for human malignant glioma, using replication-deficient retroviruses or adenoviruses. Hum Gene Ther. 2000;11:2197-205. doi:10.1089/104303400750035726

8. Immonen A, Vapalahti M, Tyynelä K, Hurskainen H, Sandmair A, Vanninen R, Langford G, Murray N, Ylä-Herttuala S. AdvHSV-tk gene therapy with intravenous ganciclovir improves survival in human malignant glioma: a randomised, controlled study. Mol Ther. 2004;10:967-72. doi: 10.1016/j.ymthe.2004.08.002
9. Westphal M, Ylä-Herttuala S, Martin J, Warnke P, Menei P, Eckland D, Kinley J, Kay R, Ram Z; ASPECT Study Group. Adenovirus-mediated gene therapy with sitimagene ceradenovec followed by intravenous ganciclovir for patients with operable high-grade glioma (ASPECT): a randomised, open-label, phase 3 trial. Lancet Oncol. 2013;14:823-33. doi: 10.1016/S1470-2045(13)70274-2

10. Li N, Zhou J, Weng D, Zhang C, Li L, Wang B, Song Y, He Q, Lin D, Chen D, Chen G, Gao Q, Wang S, et al. Adjuvant adenovirus-mediated delivery of herpes simplex virus thymidine kinase administration improves outcome of liver transplantation in patients with advanced hepatocellular carcinoma. Clin Cancer Res. 2007;13:5847-54. doi: 10.1158/1078-0432.CCR-07-0499

11. Xu F, Li S, Li XL, Guo Y, Zou BY, Xu R, Liao H, Zhao HY, Zhang Y, Guan ZZ, Zhang L. Phase I and biodistribution study of recombinant adenovirus vector-mediated herpes simplex virus thymidine kinase gene and ganciclovir administration in patients with head and neck cancer and other malignant tumors. Cancer Gene Ther. 2009;16:72330. doi: 10.1038/cgt.2009.19

12. Dewey RA, Morrissey G, Cowsill CM, Stone D, Bolognani F, Dodd NJ, Southgate TD, Klatzmann D, Lassmann H, Castro MG, Löwenstein PR. Chronic brain inflammation and persistent herpes simplex virus 1 thymidine kinase expression in survivors of syngeneic glioma treated by adenovirus-mediated gene therapy: implications for clinical trials. Nat Med. 1999;5:1256-63. doi: 10.1038/15207

13. Trask TW, Trask RP, Aguilar-Cordova E, Shine HD, Wyde PR, Goodman JC, Hamilton WJ, Rojas-Martinez A, Chen SH, Woo SL, Grossman RG. Phase I study of adenoviral delivery of the HSV-tk gene and ganciclovir administration in patients with current malignant brain tumors. Mol Ther. 2000;1:195-203. doi: 10.1006/mthe.2000.0030

14. Judy K, Eck SL. The use of suicide gene therapy for the treatment of malignancies of the brain. In: Lattime EC, Stanton LC, Eds. Gene Therapy of Cancer 2nd ed. San Diego: Academic Press 2002;pp.505-512.

15. Germano IM, Fable J, Gultekin SH, Silvers A. Adenovirus/ herpes simplex-thymidine kinase/ganciclovir complex: preliminary results of a phase I trial in patients with recurrent malignant gliomas. J Neurooncol. 2003;65:279-89.

16. Smitt PS, Driesse M, Wolbers J, Kros M, Avezaat C. Treatment of relapsed malignant glioma with an adenoviral vector containing the herpes simplex thymidine kinase gene followed by ganciclovir. Mol Ther. 2003;7:851-58.

17. Lang FF, Bruner JM, Fuller GN, Aldape K, Prados MD, Chang S, Berger MS, McDermott MW, Kunwar SM, Junck LR, Chandler W, Zwiebel JA, Kaplan RS, et al. Phase I trial of adenovirus-mediated p53 gene therapy for recurrent glioma: biological and clinical results. J Clin Oncol. 2003;21:2508-18.

18. Chiocca EA, Abbed KM, Tatter S, Louis DN, Hochberg FH, Barker F, Kracher J, Grossman SA, Fisher JD, Carson 
K, Rosenblum M, Mikkelsen T, Olson J, et al. A phase I open-label, dose-escalation, multi-institutional trial of injection with an E1B-Attenuated adenovirus, ONYX-015, into the peritumoral region of recurrent malignant gliomas, in the adjuvant setting. Mol Ther. 2004;10:958-66. doi: 10.1016/j.ymthe.2004.07.021

19. Markert JM, Medlock MD, Rabkin SD, Gillespie GY, Todo T, Hunter WD, Palmer CA, Feigenbaum F, Tornatore C, Tufaro F, Martuza RL. Conditionally replicating herpes simplex virus mutant, G207 for the treatment of malignant glioma: results of a phase I trial. Gene Ther. 2000;7:867-74. doi: 10.1038/sj.gt.3301205

20. Markert JM, Liechty PG, Wang W, Gaston S, Braz E, Karrasch M, Nabors LB, Markiewicz M, Lakeman AD, Palmer CA, Parker JN, Whitley RJ, Gillespie GY. Phase Ib trial of mutant herpes simplex virus G207 inoculated pre-and post-tumor resection for recurrent GBM. Mol Ther. 2009;17:199-207. doi: 10.1038/mt.2008.228

21. Rampling R, Cruickshank G, Papanastassiou V, Nicoll J, Hadley D, Brennan D, Petty R, MacLean A, Harland J, McKie E, Mabbs R, Brown M. Toxicity evaluation of replication-competent herpes simplex virus (ICP 34.5 null mutant 1716) in patients with recurrent malignant glioma. Gene Ther. 2000;7:859-66.

22. Papanastassiou V, Rampling R, Fraser M, Petty R, Hadley D, Nicoll J, Harland J, Mabbs R, Brown M. The potential for efficacy of the modified (ICP 34.5(-)) herpes simplex virus HSV1716 following intratumoural injection into human malignant glioma: a proof of principle study. Gene Ther. 2002;9:398-406. doi: 10.1038/sj.gt.3301664

23. Harrow S, Papanastassiou V, Harland J, Mabbs R, Petty R, Fraser M, Hadley D, Patterson J, Brown SM, Rampling R. HSV1716 injection into the brain adjacent to tumour following surgical resection of high-grade glioma: safety data and long-term survival. Gene Ther. 2004;11:1648-58. doi: 10.1038/sj.gt.3302289

24. Ropper AH. Management of raised intracranial pressure and hyperosmolar therapy. Pract Neurol. 2014;14:152-8. doi: 10.1136/practneurol-2014-000811

25. Stocchetti N, Maas AI. Traumatic intracranial hypertension. N Engl J Med. 2014;370:2121-30. doi: 10.1056/ NEJMra1208708

26. Greenwood J, Luthert PJ, Pratt OE, Lantos PL. Hyperosmolar opening of the blood-brain barrier in the energy-depleted rat brain. Part 1. Permeability studies. J Cereb Blood Flow Metab. 1988;8:9-15.

27. Neuwelt EA, Goldman DL, Dahlborg SA, Crossen J, Ramsey F, Roman-Goldstein S, Braziel R, Dana B. Primary CNS lymphoma treated with osmotic blood-brain barrier disruption: prolonged survival and preservation of cognitive function. J Clin Oncol. 1991;9:1580-90.

28. Gao Q, Chen C, Ji T, Wu P, Han Z, Fang H, Li F, Liu Y, $\mathrm{Hu}$ W, Gong D, Zhang Z, Wang S, Zhou J, et al. A systematic comparison of the anti-tumoural activity and toxicity of the three Adv-TKs. PLoS One. 2014;9:e94050. doi: 10.1371/journal.pone.0094050

29. Han Z, Hong Z, Gao Q, Chen C, Hao Z, Ji T, Hu W, Yan Y, Feng J, Liao S, Wu P, Wang D, Wang S, et al. A potent oncolytic adenovirus selectively blocks the STAT3 signaling pathway and potentiates cisplatin antitumor activity in ovarian cancer. Hum Gene Ther. 2012;23:32-45. doi: 10.1089/hum.2011.101

30. Chen C, Fang H, Han Z, Ye F, Ji T, Gong D, Li F, Zhou J, Ma D, Gao Q. Novel permissive murine immunocompetent orthotopic colon carcinoma model for comparison of the antitumoral and safety profiles of three Adv-TKs. Gene Ther. 2014;21:975-83. doi: 10.1038/gt.2014.118 